\title{
Experimental Study of Mechanical Properties of AISI 1045, AISI 1053 and AISI 4140 Steels
}

\author{
Rajesh P Verma, Durgeshwar Singh'Shwetank Avikal
}

\begin{abstract}
AISI 1045, AISI 1053 and AISI 4140 are the mostly used material for axle shaft of a vehicle. The comparative study of these materials definitely will help in selection of appropriate material for required condition. AISI 4140 has shown greater Young's modulus, yield strength and tensile strength, but moderate ductility is observed. The lesser ductility of AISI 1053 limits its usage in rear axle shaft. The ductility and Young's modulus of AISI 1045 is satisfactory, but lower strength is prime concern with it.
\end{abstract}

Keywords: AISI 1045, AISI 1053, AISI 4140, mechanical properties

\section{INTRODUCTION}

However there is rigorous development of new material, but it is no exaggeration that steel is most used material. The use of steel is found in many sectors, like automobile, aerospace, marine, architecture and many more [1]. It is most favourable material due to its high strength, hardness and availability [2]. The use of steel in axle shaft of a vehicle is irreplaceable. A shaft which rotates with the wheel, being either bolted or splined in fixed relation to it, is of a vehicle that is highly stressed.

There are many varieties of steels that are used in axle shaft. Among these materials, AISI 1045, AISI 1053 and AISI 4140 are the common steel that may found frequently as a material of axle shaft; either the case of front axle or rear axle [1-6]. The failure of shaft before its recommended life is major concern of any engineer or researcher. Therefore, an enhancement of these materials is required to attain more increased mechanical properties by heat treatment or alloying. So it becomes important to know its mechanical properties and failure phenomena to understand the behaviour of these materials.

Many researchers [3-8] have tried to study the failure mechanism of axle shaft. The reason of failure of shaft is found different in different cases. It is highly unpredictable to know that how the axle shaft will fail in general. In some study [4,5], corrosion is found as major cause of failure. In another study [6] age hardening also emerged as one of the reasons of failure. There is some cases $[7,8]$ in which the failure of the shaft is found due to stress concentration at spline.

Revised Manuscript Received on April 25, 2019.

Rajesh P Verma, Department of Mechanical Engineering, Graphic Era Deemed to be University, Dehradun, India

Durgeshwar Singh,Department of Mechanical Engineering, Graphic Era Deemed to be University, Dehradun, India

Shwetank Avikal, Department of Mechanical Engineering, Graphic Era Hill University, Dehradun, India called an axle or axle shaft. It is the one of the components

The enhancement in mechanical properties is needed to prevent the failure. In this work, a comparative study of mechanical properties (Young's modulus, yield strength, tensile strength and percentage of elongation) of AISI 1045, AISI 1053 and AISI 4140 is carried out. SEM fractography is also studied to know the nature of failure. The work will help to understand the mechanical behaviour of these materials in comparison.

II.

\section{MATERIAL AND EXPERIMENTAL WORK}

A round rod of commercial steels AISI 1045, AISI 1053and AISI 4140 of diameter of $20 \mathrm{~mm}$ were taken in this work. The chemical compositions of the materials are presented in Table 1. The tensile specimens were extracted from the rod using a CNC cutting machine and then machined to the required dimensions as shown in Fig. 1. Tensile tests were carried out at electromechanical controlled universal testing machine as per ASTM E8 standards. $0.2 \%$ offset method was applied to determine yield strength of the specimens of different materials. SEM fractographs of fractured surface of tensile specimens of all specimens were also examined at the fracture surface to identify the fracture behaviour.

Table 1: Chemical composition of material AISI 1045, AISI 1053 and AISI 4140

\begin{tabular}{|l|l|l|l|l|l|l|l|l|}
\hline $\begin{array}{l}\text { Mate } \\
\text { rial }\end{array}$ & $\mathbf{C}$ & $\mathbf{S i}$ & $\begin{array}{l}\mathbf{M} \\
\mathbf{n}\end{array}$ & $\mathbf{C r}$ & $\begin{array}{l}\mathbf{M} \\
\mathbf{o}\end{array}$ & $\mathbf{S}$ & $\mathbf{P}$ & $\mathbf{F e}$ \\
\hline AISI & 0.4 & 0.4 & 0.7 & 0.2 & 0.0 & 0.0 & 0.0 & $>9$ \\
1045 & 50 & 15 & 25 & 80 & 80 & 03 & 35 & 5.0 \\
\hline AISI & 0.5 & 0.3 & 0.8 & 0.4 & 0.1 & 0.0 & 0.0 & $>9$ \\
1053 & 10 & 10 & 25 & 10 & 00 & 40 & 25 & 5.0 \\
\hline AISI & 0.3 & 0.2 & 0.8 & 0.5 & 0.1 & 0.0 & 0.0 & $>9$ \\
4140 & 90 & 73 & 10 & 90 & 85 & 09 & 15 & 5.0 \\
\hline
\end{tabular}

Fig 1: Specimens of tensile test (Round cross section)

Published By: 


\section{RESULTS AND DISCUSSION}

The tensile strength of specimens of AISI 1045, AISI 1053 and AISI 4140 was obtained and it is reported (Fig. 2) on the basis of average of three experiments conducted on similar specimens. It was observed that all specimens of AISI 1045, AISI 1053 and AISI 4140 were broken after necking nearly at the centre of the specimens. The tensile strength of AISI 1045, AISI 1053 and AISI 4140 were estimated as $585 \mathrm{MPa}$, $650 \mathrm{MPa}$ and $1020 \mathrm{MPa}$ respectively. The yield strength (obtained using $0.2 \%$ offset method) of materials AISI 1045, AISI 1053 and AISI 4140 were found as $310 \mathrm{MPa}$, $350 \mathrm{MPa}$ and $790 \mathrm{MPa}$ respectively (Fig 3). The Young Modulus of materials AISI 1045, AISI 1053 and AISI 4140 were calculated as $200 \mathrm{GPa}, 190 \mathrm{GPa}$ and $208 \mathrm{GPa}$ respectively (Fig 4). The percentage of elongation after failure of material was measured as $15 \%, 10 \%$ and $12 \%$ for AISI 1045, AISI 1053 and AISI 4140 respectively (Fig. 5).

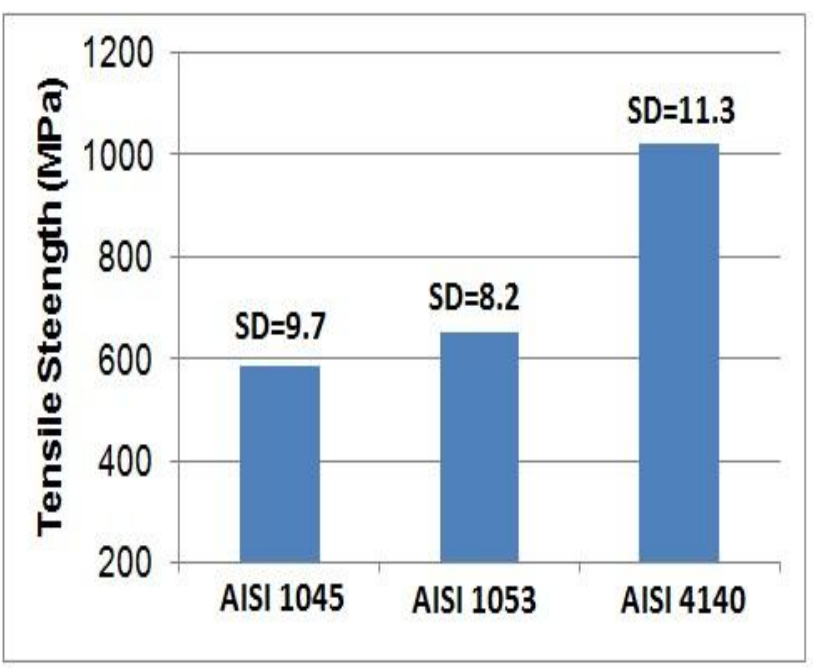

Fig. 2: Tensile Strength of materials

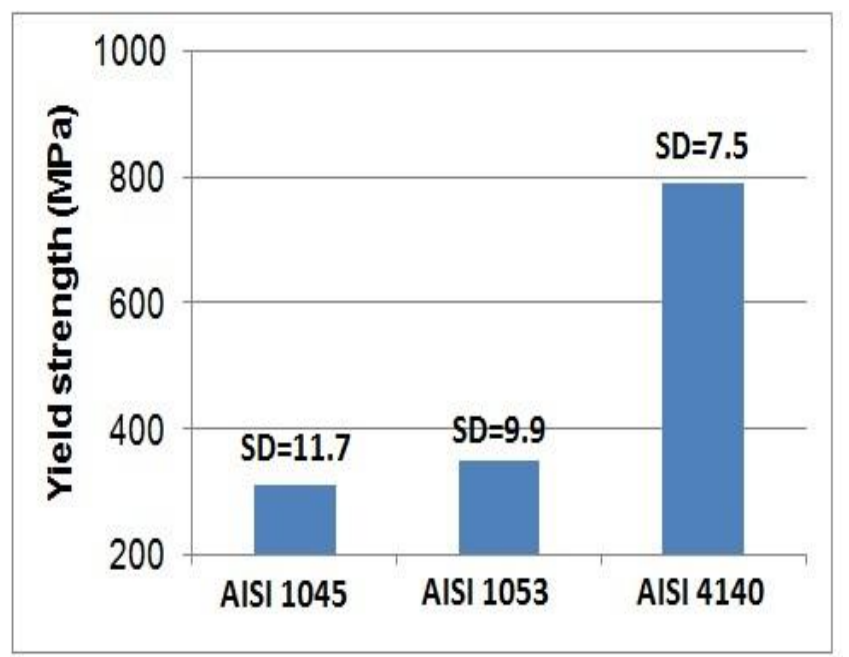

Fig. 3: Yield Strength of materials

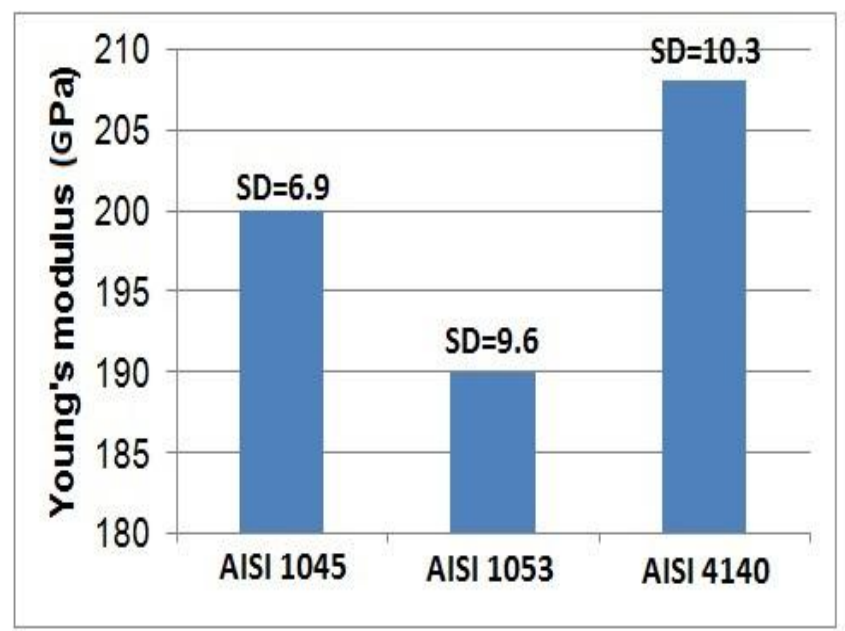

Fig. 4: Young's Modulus of materials

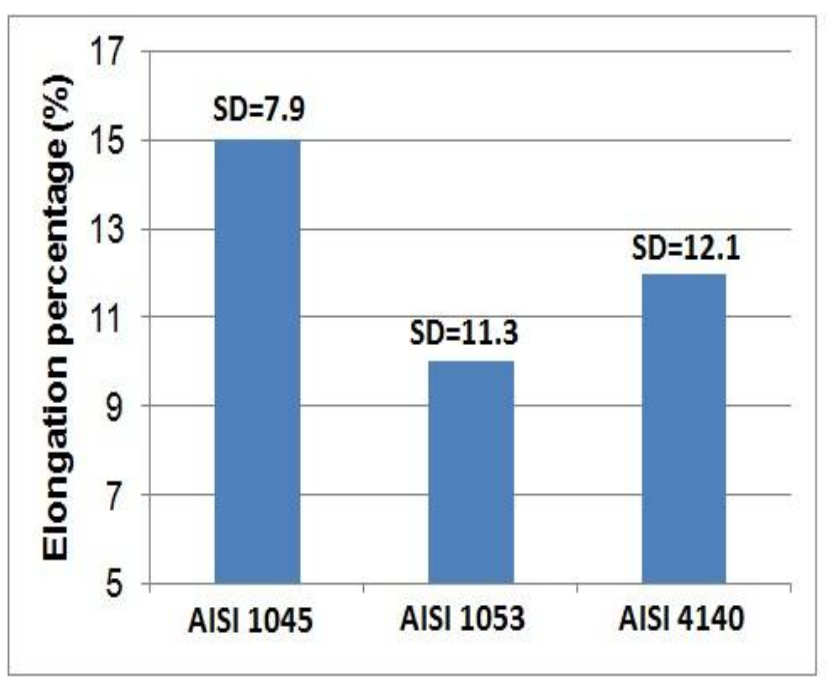

Fig. 5: Percentage of elongation of materials

The fracture behaviour of the materials was studied using scanning electron microscopy (SEM) of fractured surface of tensile specimens. The fractograph of materials are shown in Fig. 6. It is clear from the Fig. 6 that AISI 1045 exhibits clear dimples than AISI 1053 and AISI 4140 on the fractured surface.

AISI 4140 exhibits greater tensile strength, yield strength and Young's modulus. The greater content of chromium in AISI 4140 may be the reason of comparatively greater tensile strength of it [4], whereas comparatively lesser carbon composition may be the cause of higher Young's modulus and yield strength [5]. The SEM of AISI 4140 also supports the greater tensile strength due to presence of relatively finer dimples [4-6]. The comparatively lesser percentage elongation is a concern. The greater percentage of carbon in AISI 1053 may make it comparatively brittle in nature [8] and resulting in decreased elongation.

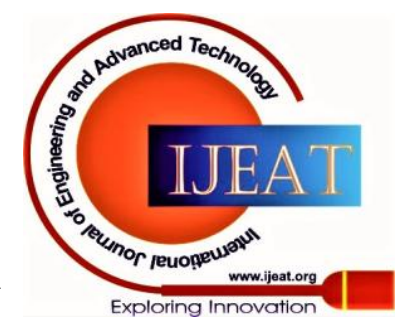




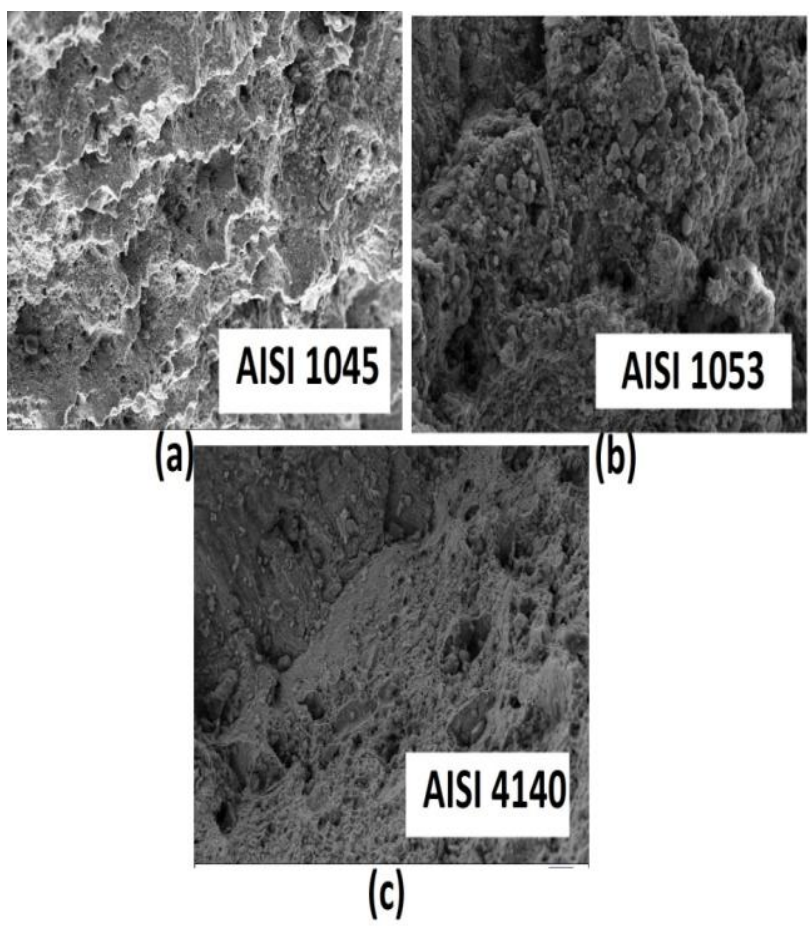

Fig. 6: SEM of fractured surface

\section{CONCLUSION}

In the present work, a comparative study of mechanical properties of AISI 1045, AISI 1053 and AISI 4140 is done. AISI showed greater Young's modulus, yield strength and tensile strength. However moderate ductility is found for AISI 4140. AISI 1053 showed lesser ductility and Young's modulus, which makes it easily prone to plastic deformation and it creates another problem like vibration, misalignment in axle shaft. The ductility and Young's modulus of AISI 1045 is satisfactory, but lower strength is prime concern with it.

\section{REFERENCES}

1. Topaç, M. M., Ercan, S., Kuralay, N. S. (2012). Fatigue life prediction of a heavy vehicle steel wheel under radial loads by using finite element analysis. Engineering Failure Analysis, 20, 67-79

2. Fuller, R. W., Ehrgott Jr, J. Q., Heard, W. F., Robert, S. D., Stinson, R. D., Solanki, K., \& Horstemeyer, M. F., Failure analysis of AISI 304 stainless steel shaft. Engineering Failure Analysis, 15(7), 2008, p 835-846.

3. Min Zhang, Xiangfei Ji, Lijun Li. (2016). A research on fatigue life of front axle beam for heavy-duty truck. Advances in Engineering Software, 91, 63-68

4. Osman Asi, Fatigue failure of a rear axle shaft of an automobile. Engineering failure analysis, 13(8), 2006, p 1293-1302.

5. G K Nanaware, M.J.Pable, Failures of rear axle shafts of 575 DI tractors, Engineering failure analysis, 10(6), 2003, p 719-724.

6. Shao, Y., Liu, J., and Mechefske, C. K. (2011). Drive axle housing failure analysis of a mining dump truck based on the load spectrum. Engineering Failure Analysis, 18(3), 1049-1057

7. Topaç, M. M., Günal, H., Kuralay, N. S. (2009). Fatigue failure prediction of a rear axle housing prototype by using finite element analysis. Engineering Failure Analysis 16 1474-1482

8. Gys van Zyl and Abdulmoshsin Al-Sahil, Failure analysis of conveyor pulley shaft. Case Studies in Engineering Failure Analysis, 1(2), 2013, p 144-155. 